\title{
LA REVISTA “EXTENSIÓN EN LAS AMÉRICAS". INFLUENCIA DE LOS EEUU EN LOS SERVICIOS DE EXTENSIÓN RURAL LATINOAMERICANOS
}

\author{
Jeremías Otero ${ }^{1}$
}

Dardo Selis ${ }^{2}$

\section{RESUMEN}

Desde finales de la década de 1940, pero principalmente durante los años '50, se crearon los Servicios Nacionales de Extensión Rural en prácticamente todos los países de América Latina. Durante este período histórico de posguerra, Estados Unidos (EEUU) desplegó una fuerte influencia en los países de la región. El objetivo de este artículo ha sido estudiar la incidencia de los EEUU en la institucionalización de los Servicios de Extensión latinoamericanos, a partir del análisis del contenido de una publicación del Instituto Interamericano de Ciencias Agrícolas (IICA): la revista "Extensión en las Américas". Este documento comienza a publicarse en 1956 y muestra la mirada respecto a la Extensión que se tenía desde el IICA. Es editada hasta 1967 y para hacer este trabajo se revisaron 28 números. Para el análisis del contenido se tomaron las siguientes categorías: estructura y diseño de la revista, línea editorial, autores (nacionalidad y pertenencia institucional), temas abordados, conceptos de extensión y desarrollo. Se verifica una presencia dominante de autores estadounidenses en los artículos con mayor contenido conceptual, y un lugar privilegiado de los EEUU en las editoriales, elementos que demuestran la hegemonía ejercida a nivel conceptual en el campo de la Extensión Rural Latinoamericana.

Palabras clave: América Latina, Estados desarrollistas, IICA.

\section{REVISTA "EXTENSIÓN EN LAS AMÉRICAS". INFLUÊNCIA DOS EUA NOS SERVIÇOS DE EXTENSÃO RURAL NA AMÉRICA LATINA}

\section{RESUMO}

Desde o final da década de 1940, mas principalmente durante a década de 1950, foram estabelecidos os Serviços Nacionais de Extensão Rural em quase todos os países da América Latina. Durante este período histórico do pós-guerra, Estados Unidos (EUA) mostrou uma forte influência sobre os países da região. Tendo como objetivo estudar a influência dos EUA na institucionalização dos serviços de

\footnotetext{
1 Ingeniero agrónomo (UNLP). Magister en Procesos Locales de Innovación y Desarrollo Rural (UNLP). Docente Curso de Extensión rural, Departamento de Desarrollo Rural - Facultad de Ciencias Agrarias y Forestales (UNLP). Becario CONICET.

2 Ingeniero agrónomo (UNLP). Profesor titular del Curso de Extensión rural, Departamento de Desarrollo Rural - Facultad de Ciencias Agrarias y Forestales (UNLP).
} 
extensão na região, a partir da análise do conteúdo de uma publicação do Instituto Interamericano de Ciências Agrícolas (IICA): a revista "Extensión en las Américas". Este documento começou a ser publicado em 1956, e mostra as perspectivas sobre a extensão que existia no IICA. É editado até 1967 e para fazer este trabalho foram revisados 28 edições publicadas durante este período. Para a análise de conteúdo foram tomadas as seguintes categorias: estrutura e design da revista, editorial, autores (nacionalidade e filiação institucional), temas discutidos, e os conceitos de extensão e desenvolvimento. É verificada a presença dominante dos autores americanos nos artigos com conteúdo conceitual e um lugar privilegiado nos EUA nos pontos de vista dos editores, elementos que demonstram a hegemonia exercida em nível conceitual no campo da Extensão Rural em América Latina no período analisado.

Palavras-chave: América Latina, IICA, nacional-desenvolvimentismo.

\section{INTRODUCCIÓN}

Una vez finalizada la Segunda Guerra Mundial, EEUU desplegó una muy fuerte influencia sobre los países latinoamericanos, a los que se les asignó el rol de proveedores de materias primas agrícolas, para lo cual deberían incrementar su productividad a través de la modernización de la agricultura. La modernización ha sido concebida como el proceso que lleva a las sociedades tradicionales hacia la modernidad y se refleja en una serie de cambios: urbanización, industrialización, diferenciación social, crecimiento económico, entre otros (ESCOBAR, 1994). El supuesto que América Latina estaba poblada de masas de campesinos que había que sacar de la ignorancia, a través del acceso a la educación no formal y siguiendo el modelo conceptual desarrollado en EEUU durante más de 50 años, encuentra su solución a través de la instalación de los Servicios de Extensión Rural.

Por otro lado, en Latinoamérica se inicia una etapa donde uno de los elementos significativos se vincula a la creación de la CEPAL -Comisión Económica para América Latina- (en 1948) que influyó fuertemente sobre los estados de la región en la década de 1960. Este tipo de estado, denominado desarrollista, fue intervencionista y propició economías mixtas con ingreso de capitales extranjeros, con la finalidad de producir un "despegue interno". De esta manera, el desarrollismo postergó al Estado Benefactor en pos de la dinamización de la economía (GRACIARENA, 2000).

Respecto a las políticas de desarrollo agropecuario, durante esos años, según Barsky (1990) predominaron dos políticas: a) de desarrollo de la comunidad; y b) de reforma agraria. La política de "desarrollo de la comunidad" se ha incorporado formalmente al uso internacional para designar aquellos procesos donde los esfuerzos de una población se suman a los de su gobierno para mejorar las condiciones económicas, sociales y culturales de las comunidades (Naciones Unidas, 1960 en BARSKY, 1990). Respecto a las políticas de reforma agraria, a partir de la década de 1950, en América Latina se iniciaron numerosos procesos de modificación en la tenencia de la tierra. Sin embargo, el grado de transformación de las estructuras agrarias fue muy diferente en cada uno de los casos. Más allá de las experiencias revolucionarias, donde fue el pueblo quien se alzó en la conquista de la tierra (México o Bolivia), desde los organismos oficiales también se "recomendaba", con algunas salvedades, iniciar este tipo de procesos. Esta fue la principal razón que incitó a gran parte de los países de la región a llevar formalmente adelante políticas de reforma agraria, aunque en la mayoría de los casos el cambio producido fue 
superficial y casi insignificante. La preocupación evidente de EEUU y de los gobiernos latinoamericanos era impedir que se expandiera en el continente el "virus" de la revolución cubana (SAMPAIO, 2005).

Como afirma Alemany (2012) la institucionalidad que sostuvo las políticas de desarrollo agropecuario impulsadas por los EEUU, se vinculó principalmente a la FAO (Food \& Agriculture Organization), perteneciente a la ONU (Organización de las Naciones Unidas), y al $\mathrm{IICA}^{3}$ (Instituto Interamericano de Ciencias Agrícolas) correspondiente a la OEA (Organización de Estados Americanos), ambas organizaciones creadas en la década de 1940. El IICA cumplió un rol central al ser el encargado de difundir la propuesta en los diferentes países, asignando importantes recursos para ello.

Es en este contexto que a partir de 1956 comienza a publicarse la revista "Extensión en las Américas". Este documento es el principal registro escrito que da cuenta de la mirada respecto a la Extensión que se tenía desde el IICA. Es publicada durante doce años, desde 1956 hasta 1967, cuando es discontinuada y reemplazada al año siguiente por la revista "Desarrollo Rural en las Américas".

En este sentido, el objetivo de este artículo es estudiar la influencia de los EEUU en la institucionalización de los Servicios de Extensión en la región, a partir del análisis del contenido de la publicación del Instituto Interamericano de Ciencias Agrícolas (IICA): la revista "Extensión en las Américas".

La metodología utilizada se basó en el análisis de contenido ${ }^{4}$ de la publicación, focalizándose en las relaciones externas (contexto histórico y político), sus características internas (valores, principios y mensajes que pretende transmitir), y sus sentidos ideológicos (significados). La unidad de análisis fue la revista "Extensión en las Américas", publicada por el Servicio de Intercambio Científico del IICA, en virtud de un convenio suscripto con la Agencia de Desarrollo Internacional de los EEUU. La población total de revistas estuvo compuesta por 51 números, de ese total, para la realización del trabajo, la muestra se conformó por 28 ejemplares ${ }^{5}$ (55\%) correspondientes al período en que fue editada (desde 1956 hasta 1967). Para el análisis, se tomaron las siguientes categorías: estructura y diseño de la revista, línea editorial, autores (nacionalidad y pertenencia institucional), temas abordados, y conceptos de extensión y desarrollo.

\section{EL CONTEXTO HISTÓRICO: EL IICA Y LOS SERVICIOS DE EXTENSIÓN RURAL EN AMÉRICA LATINA}

A fin de avanzar con el objetivo propuesto, se considera necesario presentar aquellos elementos del contexto que son significativos. En ese sentido, para poder comprender la influencia de los EEUU en los enfoques asumidos por los Servicios de Extensión en Latinoamérica durante el período de posguerra, resulta

\footnotetext{
${ }^{3}$ El IICA, en 1981 cambia su denominación, el Instituto Interamericano de Ciencias Agrícolas, pasa a llamarse Instituto Interamericano de Cooperación para la Agricultura.

${ }^{4} \mathrm{El}$ análisis de contenido es entendido como un conjunto de procedimientos interpretativos de productos comunicativos (mensajes, textos o discursos) que proceden de procesos singulares de comunicación previamente registrados, y que, basados en técnicas de medida, a veces cuantitativas (estadísticas basadas en el recuento de unidades), a veces cualitativas (lógicas basadas en la combinación de categorías) tienen por objeto elaborar y procesar datos relevantes sobre las condiciones mismas en que se han producido aquellos textos, o sobre las condiciones que puedan darse para su empleo posterior (Piñuel Raigada, 2002).

5 Los números analizados fueron aquellos que pudieron ser recuperados, en función del largo tiempo transcurrido luego de su publicación; siendo los números consultados, los siguientes: Año 1956, №1, 2,3 y 4; Año 1957, Nº 1 y 2; Año 1958, Nº1, 2, 3, 4,5 y 6; Año 1959, №1, 3, 4, 5 y 6; Año 1960, Nº 5; Año 1961 Nº 3 y 4; Año 1962, N 4; Año 1963, Nº 2 y 3; Año 1964, N¹ y 2; Año 1966, №1, 3 y 4; Año 1967 ํ3 y 4.
} 
necesario revisar los aspectos institucionales sobre los que se sustentó la estrategia implementada.

\subsection{El servicio cooperativo de extensión rural de los Estados Unidos}

Para entender la influencia ejercida por los EEUU en materia de extensión agrícola, es fundamental conocer su propia organización y las acciones de extensión realizadas por el "Servicio Cooperativo de Extensión".

Respecto a sus inicios, debemos remontarnos al Sistema del Land-grant College, que fue creado mediante varios actos legislativos, orientados a recibir los beneficios otorgados por las "Leyes Morril de 1862 y 1890", cuya misión original fue la de enseñar técnicas de agricultura, como una forma práctica para que las clases trabajadoras rurales tuvieran acceso a una educación liberal y práctica.

Con el tiempo, dicho estatus jurídico propició ayudas federales en la forma de otorgamiento de tierras en cada estado para el establecimiento de una institucionalidad pública que permitiera desarrollar la intención del legislador. Para cumplir el mandato, fueron establecidas en dichas tierras, estaciones experimentales, y el tamaño de las inversiones era calculado en función del número de productores en cada región. De igual manera, para la diseminación de la información técnica y materiales generados, se creó el "Sistema Cooperativo de Extensión Rural" (SCER), directamente asociado al Sistema del Land Grant College creado por la Ley Federal conocida como "Smith-Lever Act" en 1914. Dicho sistema recibía no sólo fondos de origen nacional, sino también estatales / federales (Matching funds), y posteriormente también incluyó e incluye hoy, aportes privados y de asociaciones de productores (PUERTA, 1996).

Los objetivos del Servicio Cooperativo de Extensión Rural (SMITH Y WILSON, 1930) eran los siguientes:

- Incrementar el ingreso neto del agricultor a través de una producción y una comercialización más eficiente y el mejor uso de capitales y créditos.

- Promover mejores y más elevados estándares de vida en la explotación.

- Desarrollar líderes rurales.

- Promover la vida mental, social, cultural y recreativa de la población rural.

- Implantar el amor a la vida rural en los jóvenes rurales.

- Sensibilizar al público con el lugar de la Agricultura en la vida nacional.

- Ensanchar la visión de la población rural y de la Nación sobre los temas rurales.

- Mejorar la vida educativa y espiritual de la población rural.

Detrás de la intervención del Estado, práctica y orientada a la acción, difundiendo conocimientos útiles relacionados con la producción y la vida rural para mejorar la calidad de vida de las poblaciones rurales, estaba la necesidad de cambiar las mentalidades de los campesinos para introducir la "civilización científica" en el campo. De este modo el papel histórico realizado por la extensión rural, fue sentar las bases para desarrollar el modo industrial de los recursos naturales (GUZMÁN, 2006).

\subsection{EI IICA y la extensión rural}

Se reconocen dos hitos que incidieron en la creación del IICA, estos son: la $1^{a}$ Conferencia Interamericana de Agricultura, en 1930 y en 1940, la realización del $8^{\circ}$ Congreso Científico Americano, en Washington DC, donde se propone la creación de un Instituto de Agricultura Tropical (IICA, 1992). 
En ese marco, en 1942 se define que será Turrialba, Costa Rica, la sede del Instituto que pasará a denominarse Instituto Interamericano de Ciencias Agrícolas (IICA). Y en 1943, Henry Wallace, vicepresidente de los EEUU, es quien coloca la primera piedra del edificio donde se instalará el Instituto.

Durante los primeros años son pocos los países miembros (sólo algunos estados centroamericanos) que acompañan la iniciativa de los EEUU. Es recién a partir de la década siguiente (1950) mediante la puesta en marcha del Servicio de Intercambio Científico, el "Proyecto 39" y el contrato con la Administración de Cooperación Internacional de los EEUU, que el Instituto empieza a aumentar el número de países miembros y a tener mayor presencia institucional en la región.

En 1950, la OEA aprueba el Programa de Cooperación Técnica, y es en el marco de este programa que en 1951 se autorizó la iniciación de cinco proyectos, dentro de los cuales se encontraba el Proyecto 39 "Enseñanza técnica para el mejoramiento de la agricultura y la vida rural", dirigido por el IICA hasta su finalización en 1966. En ese marco, se formaron 10.000 profesionales en distintos temas: bibliotecología, dasonomía, educación para el hogar, extensión agrícola, fitotecnia, horticultura, estadística, sociología, zootecnia, pasturas, suelos, etc. (COTO, 1967). Por otro lado, también se le asigna al IICA la ejecución de los Proyectos 201 de Crédito Agrícola iniciado en 1961; y 206 de Reforma Agraria, iniciado 1962. Estos proyectos finalizan en 1967 y se integran bajo el nuevo Programa Interamericano de Desarrollo Rural y Reforma Agraria (IICA, 1992).

\subsection{Servicios de extensión rural latinoamericanos: surgimiento y concepción}

Una vez finalizada la Segunda Guerra Mundial, Estados Unidos se marca como objetivo, el apoyo al Desarrollo de otros países, debido a razones políticas vinculadas al avance del socialismo, y económicas, relacionadas a la amenaza de recesión interna. La convergencia de esta necesidad económica y de la voluntad política de consolidar su área de influencia en el rejuego internacional de postguerra, lleva a diversas agencias norteamericanas, como la Fundación Rockefeller, Fundación Ford, y el Instituto de Asuntos Interamericanos, a apoyar programas de educación agrícola tendientes a acelerar el crecimiento económico de esta parte del mundo (CASTILLO; LATAPI, 1984).

Los países de la Región acometieron, bajo la influencia del llamado "modelo Cepalino", una agresiva etapa de industrialización y sustitución de importaciones, para lo cual se tomó como prioritaria la contribución del sector agropecuario mediante la producción de alimentos "baratos" para las crecientes poblaciones urbanas, y la correspondiente mano de obra que alimentaba las primeras industrias. Por supuesto, el eje de este esfuerzo fue el tecnológico, ya que en muchos casos la productividad media de cultivos tradicionales y especies animales estaba muy por debajo de la media mundial, por lo que era necesario elevarla. El esfuerzo era "hacia adentro", aún no emergía el modelo exportador agroalimentario, razón por la cual los alimentos básicos eran el objetivo principal.

Se iniciaba el proceso de industrialización de la agricultura, y no podía este sector prescindir de políticas e instrumentos capaces de asegurar el consumo creciente de estos bienes industriales desarrollados para la producción agrícola (CAPORAL y COSTABEBER, 1994).

Desde el punto de vista técnico, estas políticas de industrialización temprana representaron el estímulo que se requería para desarrollar en los países de América Latina, un modelo único de Investigación - Extensión a nivel nacional, cuyos inicios fueron marcados por el establecimiento de los primeros INIA, o 
Institutos Nacionales de Investigación y Extensión. En sus comienzos, mediante esfuerzos de cooperación desarrollados por el Gobierno estadounidense y con el apoyo de varias fundaciones (Ford, Kellog, Rockefeller entre otros, y la Agencia Internacional para el Desarrollo, AID). Mediante esta cooperación y con el financiamiento del Banco Interamericano de Desarrollo (BID) primordialmente, y también del Banco Mundial, se desarrollaron ambiciosos programas de capacitación de profesionales latinoamericanos principalmente en universidades norteamericanas. Paralelamente, los Estados Unidos comisionaron varios centenares de profesionales a los recién creados INIA en la Región, desde finales de los años sesenta hasta mediados de los setenta, para prestar importantes servicios de cooperación técnica, orientados a incrementar la capacidad de la Región para la Investigación y la Extensión. Inicialmente iban a ser Europa, Latinoamérica y Oriente Medio las Regiones destinatarias de la cooperación norteamericana en extensión. Más tarde dicha ayuda sería dirigida a Asia y África (PUERTA, 1996).

La asistencia norteamericana en Extensión a Latinoamérica y Europa se realizó fundamentalmente por dos vías. Por un lado, mediante el asesoramiento directo con expertos asignados a países específicos; y por el otro, a través de la formación de personas de los países afectados, en Estados Unidos y en otros países (Holanda: Centro Agrícola Internacional de Wageningen; España: Centro Internacional de Capacitación sobre Extensión Rural y Costa Rica: IICA).

El personal de Extensión estadounidense ha servido como asesor durante algún tiempo en aproximadamente 80 países. Su trabajo consistió principalmente en asistir activamente a los gobiernos en la creación y organización de Servicios de Extensión, formar al personal de estos servicios y asesorar en el desarrollo de programas de extensión para encontrar las necesidades de la población rural (MAUNDER, 1966).

En Ecuador, se inician acciones de extensión en 1946 (RUIZ, 1957), a través de los clubes 4-F; y en 1952, en un convenio entre Ecuador y los EEUU se crea el Servicio Cooperativo Interamericano de Agricultura (SCIDA) (TORRES, 1958), unificando de esta manera, el servicio de extensión rural en ese país. La extensión rural fue introducida en Brasil a partir del año 1948, como consecuencia de la acción directa de organizaciones públicas y privadas de EEUU, con la asesoría de expertos formados en el seno de la sociología institucionalizada en aquél país (CAPORAL, 2001). En Guatemala, también en el marco del SCIDA, en 1955 se inician las acciones de extensión (RUBIO, 1956). Honduras comienza con su servicio de extensión a nivel nacional en 1951, mediante el Servicio Técnico Interamericano de Cooperación Agrícola (STICA), constituido con el apoyo de los EEUU (CÁCERES, 1956). En Nicaragua, el Servicio de Extensión Agrícola comenzó en 1949 "cuando el Sr. Paul G. Adams del Servicio de Extensión del Estado de Oklahoma, EEUU, llegó a Nicaragua a promover y dirigir este movimiento" (ROBERTS, 1956); y en Argentina en 1956, con la creación del Instituto Nacional de Tecnología Agrícola (INTA), se inicia el servicio de extensión público y con cobertura nacional. Para el mismo período también fueron creados los servicios de extensión de algunos otros países latinoamericanos. 


\section{Cuadro 1 - Año de creación de los servicios de extensión rural en América Latina}

\begin{tabular}{ll}
\hline País & Año \\
\hline Perú & 1943 \\
Venezuela & 1946 \\
Brasil & 1948 \\
Bolivia & 1948 \\
Nicaragua & 1949 \\
Honduras & 1951 \\
Paraguay & 1951 \\
Ecuador & 1952 \\
Colombia & 1954 \\
Guatemala & 1955 \\
Argentina & 1956 \\
\hline
\end{tabular}

Fuentes: RUIZ (1957); TORRES (1958); RUBIO (1956); CÁCERES (1956); ROBERTS (1956); BARRIENTOS (2002); CAPORAL (2001).

\section{RESULTADOS Y DISCUSIÓN}

En la editorial del primer número de la revista queda claro que la misma es dirigida hacia extensionistas de los servicios latinoamericanos que, con la ayuda de EEUU, se estaban instalando en la región:

\footnotetext{
Hasta el momento los extensionistas latinoamericanos no tienen acceso a la literatura de Extensión de los Estados Unidos y Europa [...] el IICA en colaboración con la International Cooperation Administration de los EEUU, decidió publicar esta revista [...] (Volumen I, N¹, 1956).
}

La publicación de carácter bimestral fue editada, diseñada e impresa en el IICA y se caracterizó por un lenguaje claro, sencillo y directo, siendo los formatos más utilizados, los artículos de opinión, las noticias, las crónicas y la editorial. Las portadas muestran generalmente imágenes del trabajo del extensionista, con un diseño moderno para la época, con variación de las formas y tamaños de las fotografías e ilustraciones, un uso amplio de espacios blancos, un diseño balanceado y bajada de título. Si bien está dirigida a profesionales de la extensión, se observa un esfuerzo por darle lecturabilidad a través de diferentes recursos de mediación, basados en artículos cortos y sin apelar a un lenguaje cientificista. Se distribuyó gratuitamente a través de las Misiones de Operaciones de los Estados Unidos que funcionaban en los países latinoamericanos. 
Figura 1 - Tapa del volumen I, número 1, de 1956.

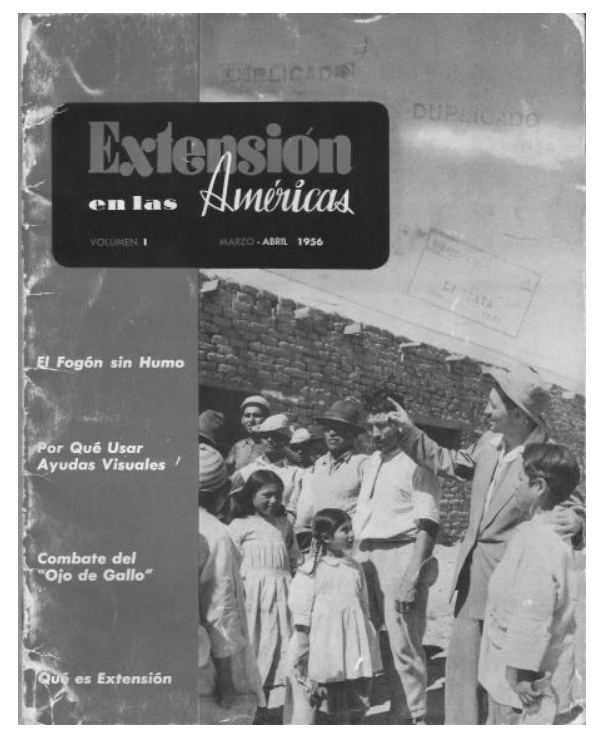

Básicamente, la revista estaba constituida por artículos (de opinión, noticias, crónicas) y secciones: "Columna de Editor", "Su carta dice [...]", "La Ciencia a su servicio", "De aquí y de allá", y "Revisiones y compendios para usted". La extensión de los artículos era corta (entre dos y tres páginas), y cada número incluía entre seis y diez artículos. En promedio, la cantidad de páginas de la revista era de 30 .

Respecto a la Editorial, el contenido predominante estuvo asociado por un lado, a la actualidad del Instituto y por el otro, a la introducción y justificación de los temas comprendidos en cada número. Revisando las "Columnas del Editor" de varios números de la revista, se rescatan las siguientes frases, que dan cuenta de la influencia de los EEUU:

La mayoría de los extensionistas latinoamericanos, como tales, son producto de su propio esfuerzo y de su amor por esta profesión. Han sido ayudados generosamente en su empeño, por los especialistas norteamericanos que han venido a la América Latina (Volumen I, N³).

Ellas (las Mejoradoras del Hogar) han realizado una labor digna de encomio en esta parte del mundo. Comenzaron su trabajo admirable en los EEUU y han logrado realizaciones tangibles [...] Desbordaron sus conocimientos y sus actividades por todo el mundo, recibiendo la América Latina el beneficio de su proximidad al poderoso país del Norte (Volumen III, $\mathrm{N}^{\circ} 6$ ).

El Programa de Adiestramiento de Extensionistas en Comunicaciones, ADECO [...]. Su adopción por el IICA es el resultado de un proceso de estudio y análisis de las experiencias con el mismo programa en los EEUU (Volumen IV, $\left.\mathrm{N}^{\circ} 4\right)$. 
Estos fragmentos dan cuenta del lugar privilegiado que ocupaba EEUU en las visiones de los Editores de esta revista. Abundan los ejemplos donde se interpela a los lectores a leer y escuchar las voces de los investigadores y expertos estadounidenses, ya que son estos los que con su experiencia y profesionalidad iluminarán el camino de los extensionistas latinoamericanos para "sacar del atraso" a los campesinos.

El resto de las secciones se describen a continuación:

- "De aquí y de allá", incluyó noticias institucionales vinculadas a la creación de los servicios de extensión en los diferentes países de América Latina, la movilidad de los funcionarios del IICA, etc.

- La sección "Revisiones y compendios para usted", estuvo constituida por una selección bibliográfica, donde se presentan libros y folletos sobre cultivos, ganadería, problemas fitosanitarios, suelos, construcciones rurales, materiales de extensión, etc.

- "La ciencia a su servicio", fue una sección dedicada a presentar los aportes del conocimiento científico a la agricultura, la ganadería, el trabajo del extensionista, la comunicación y educación, etc.

- "Su carta dice..." era el espacio para la expresión de los lectores. Las cartas, principalmente, eran enviadas por funcionarios y representantes de instituciones y organizaciones de distintos países de América Latina.

En relación a los artículos, fueron clasificados en función de sus contenidos, en:

a) Conceptuales: incluyeron nociones básicas vinculadas en mayor o menor medida, al trabajo de extensión (34\% del total de los números analizados);

b) Institucionales: descripción de la organización e institucionalización de las actividades relacionadas a la extensión en cada país $(28,5 \%$ del total de los números analizados);

c) Metodológicos: las metodologías y herramientas de planificación, comunicación y educación ( $22 \%$ del total de los número analizados);

d) Experiencias: el relato de experiencias concretas de las acciones dirigidas al mejoramiento de la producción, la economía doméstica y las juventudes rurales (15,5\% del total de los números analizados).

En un total de 28 números examinados, fueron encontrados 67 artículos que se clasificaron con contenido conceptual vinculado a la extensión. Fundamentalmente, estos artículos comprenden reflexiones a modo de ensayos, sobre distintos temas: definición y filosofía de la extensión, la persuasión, el crédito agrícola, el hogar rural, la mujer en el desarrollo agrícola, economía doméstica, extensión y desarrollo, desarrollo de la comunidad, clubes juveniles, juventudes rurales, relaciones públicas en las organizaciones de productores, planificación en extensión, reforma agraria, y líderes, entre otros. Del total, el 55\% fue escrito por autores de origen estadounidense. Los emisores privilegiados que aparecen en la revista son los funcionarios del IICA y los especialistas de EEUU - primordialmente pertenecientes a Universidades de distintos Estados del país del norte. Los campesinos, jóvenes y amas de casa sólo aparecen en las fotos.

En los números analizados, los autores que aparecen con mayor frecuencia presentando artículos con contenido conceptual sobre la extensión rural son Joseph Di Franco y Earl Jones. Para ejemplificar el perfil de los emisores privilegiados, entendemos conveniente mencionar algunos de sus antecedentes principales: 
- Joseph Di Franco escribe sobre la "esencia" de la extensión y el desarrollo de la comunidad. Fue un norteamericano de origen italiano. Se educó en las instituciones del Estado de Ohio, donde también trabajó en el Servicio de Extensión. Realizó el doctorado en Educación en la Universidad de Columbia, y luego trabajó como Profesor en la Universidad de Cornell. En 1958 ingresó al IICA y ocupó cargos de alta jerarquía como "Jefe de la Disciplina de Economía y Ciencias Sociales".

- Earl Jones, también estadounidense, fue Doctor en Ciencias Sociales, formado en la Universidad de Montana - EEUU, escribe fundamentalmente sobre juventud y liderazgo. Su tesis doctoral se tituló: "Un estudio de los programas de la juventud en las Américas", publicada en 1962.

Los artículos con contenido institucional fueron un total de 56 (el 28,5\%), contemplaron información referida a clubes juveniles, cooperativas, historia y creación de programas y servicios de extensión nacionales, realización de cursos de distintos temas vinculados a la extensión, congresos o conferencias, entre otros. A su vez, se refieren a una gran variedad de países de América Latina, ya que mencionan a: Panamá, Cuba, Nicaragua, Guatemala, Costa Rica, Ecuador, Perú, Argentina, Paraguay, Brasil, Surinam, Venezuela, Uruguay, El Salvador y Colombia; además de los EEUU.

Respecto a los artículos con contenido metodológico, suman un total de 43. Incluyeron recomendaciones prácticas respecto a distintas cuestiones del trabajo del extensionista. Estuvieron asociadas a herramientas de: a) comunicación y educación: uso de ayudas audiovisuales, radio, periódicos, lecturabilidad, demostración de resultados; y b) de planificación: diagnóstico, evaluación, etc. Respecto al origen de los autores de estas notas, un $60 \%$ es estadounidense.

Por otro lado, cabe destacar que la revista tuvo números especiales donde se trataron temas que estuvieron alineados y en colaboración a definiciones políticoinstitucionales propias de la OEA, en contextos históricos específicos. En ese sentido, algunos de esos temas priorizados fueron: la reforma agraria y las juventudes rurales.

En 1959 en coincidencia con la Revolución Cubana, la revista dedicó un número especial a la Reforma Agraria. En su editorial, plantean cuál es el sentido que debe atribuirse a la extensión rural como parte de las políticas de Reforma Agraria en América Latina.

La Reforma Agraria no se soluciona simplemente con eliminar o resolver la existencia del minifundio, ni del Latifundio, en el sentido Latinoamericano de estos conceptos. La Reforma Agraria como lo indican los investigadores, se debe solucionar también mediante programas de educación. Darles tierra a los labriegos ignorantes sin educarlos para la nueva función a que han sido llamados, equivale a condenarlos al fracaso [...] (Volumen V, 1959, n. 5).

En 1962 en el marco de los inicios de la Alianza para el Progreso, se conformó el Comité Técnico Interamericano para la Juventud Rural, nombrado por la OEA. En ese sentido en 1963, la revista dedica un número especial relacionado a las juventudes rurales.

En América Latina más de 30 millones de jóvenes rurales en las edades de 10 a 19 años carecían de las condiciones mínimas en cuanto a oportunidades de educación, ingreso 
familiar, higiene, salud y vivienda [...] De estos jóvenes va a depender en su mayor parte el desarrollo económico de esos países ya que ellos serán los agricultores, las amas de casa y los líderes o guías de sus comunidades (Volumen VIII, n. 2, 1963).

Para ese entonces, uno de cada 300 jóvenes participaba de los clubes juveniles en todo Latinoamérica. Mientras que en EEUU el número de socios de los clubes 4-H superaba los 2 millones, en el resto de los países de América Latina (en 19 países donde estaban formados), los clubes juveniles rurales, apenas superaban los 100.000 socios. En este marco, desde la OEA, se hace un fuerte llamamiento a los países de la región a establecer programas de atención y estímulo para las juventudes rurales.

Por otro lado, en 1962, la revista dedica un número especial al liderazgo y su importancia en la extensión. El mismo número menciona que el Servicio Cooperativo de Extensión en los EEUU en 1952, contaba con 1.200.000 líderes voluntarios, poniendo en evidencia el papel asignado a los líderes en dicho país.

El número de agentes de extensión es muy reducido en $\mathrm{AL}$ en relación a la población rural, el trabajo con líderes toma pues mayor importancia. El agente, por medio de ellos podrá ampliar considerablemente su labor educativa, y la población rural aceptará mejor las nuevas prácticas cuando estas hayan sido acogidas por los líderes. Además a través de ellos, el agente agrícola, la mejoradora del hogar, el agente de clubes podrán conocer mejor cuáles son las necesidades [...]" También por medio de los líderes es más fácil despertar en la gente el interés de "ayudarse a sí misma" y no esperar a que otros les resuelvan sus problemas (Volumen VII, n. 4, 1962).

El IICA, a través del Departamento de Economía y Ciencias Sociales financió investigaciones con el propósito de desarrollar metodologías para "descubrir" lideres formales e informales en zonas rurales; sobre difusión y adopción tecnológica y cambio cultural (Arce, 1963), encontrando que la educación, posición económica y social, costumbres, tradiciones y valores culturales de los individuos pueden ser factores relacionados con la aceptación o rechazo de ciertas prácticas o con la aceptación lenta o rápida de las mismas. En este sentido, recorriendo la revista podemos encontrar suficientes evidencias de la influencia de la psicología conductista, la antropología cultural y la sociología rural americana en el modelo de Extensión Rural impulsado por el IICA.

Por otro lado, en el análisis del contenido de la revista, pueden reconstruirse las diferentes acciones realizadas en el marco del Proyecto 39. Desde allí se implementó una estrategia que consistía en capacitaciones de técnicos en diferentes países de la región, a través de Cursos para extensionistas dictados inicialmente por profesores de Universidades de EEUU, visitas de funcionarios latinoamericanos al Servicio de Extensión Cooperativo (SEC) de EEUU, investigaciones, cursos de postgrado a nivel de maestría, traducciones de libros que solo estaban disponibles en inglés, traducciones de materiales de difusión destinados a extensionistas elaboradas por el SEC, y apoyo económico a proyectos pilotos.

La estrategia de formación de recursos humanos con este nuevo enfoque en la región, se inicia en el año 1952 en Uruguay con el Primer curso Internacional 
de Extensión Agrícola, auspiciado por el IICA, en el que participan extensionistas de la región que luego actuarán como multiplicadores de la propuesta en sus países.

Entre el 1956 y 1958 el IICA envió a sus técnicos a participar de los cursos "Train the trainer" (adiestrar al adiestrador) en los EEUU, luego en 1959 se decide adaptar este programa de comunicaciones a las "condiciones latinoamericanas", financiado por la Administración de Cooperación Internacional de los EEUU. Así nació el programa ADECO (Adiestramiento de Extensionistas en Comunicaciones) con cuatro unidades: comunicación básica, oral, escrita y audio-visual. El responsable principal para la realización del curso fue el Dr. John Morrow, de Washington D.C. La primera edición de este programa se realizó en enero de 1960.

Luego de estos cursos iniciales se avanza en la formación de especialistas en Extensión a través del dictado en Costa Rica de la Maestría en Extensión Rural en el año 1964, lo que también genera una serie de investigaciones específicas como producto de las Tesis de los estudiantes. Luego, los estudios de posgrado se extienden a otros países. Por ejemplo, en Argentina en 1968, se inicia en la Escuela para Graduados en Ciencias Agropecuarias (que funcionó en Castelar), la capacitación de técnicos argentinos, brasileños, uruguayos y paraguayos, mediante un convenio entre el IICA, el INTA y las Universidades Nacionales de Buenos Aires y La Plata.

La influencia de los EEUU también se verifica en la similitud existente entre la estructura de los diferentes servicios de extensión entre sí, y respecto a la organización del SEC. En este marco, las acciones estuvieron destinadas a las familias rurales, siendo tres (3) los principales componentes en prácticamente todos los servicios instalados en ese período: Asistencia técnica en producción agropecuaria, Clubes juveniles y Programas para el Mejoramiento del Hogar Rural. En cuanto a los programas para las "Juventudes", los mismos estaban destinados a los jóvenes del campo, que se organizaban a través de la figura de los "Clubes" donde encontraban un espacio de capacitación y socialización.

\section{Cuadro 2 - Clubes juveniles en los programas de extensión agrícola.}

\begin{tabular}{ll}
\hline Clubes Juveniles & País \\
\hline $\begin{array}{l}\text { Clubes 4-F } \\
\text { (Fe, Fecundidad, Fortaleza y Felicidad) }\end{array}$ & Ecuador \\
$\begin{array}{l}\text { Clubes 4-S } \\
\text { (Salud, Saber, Sentimientos y Servicio) } \\
\text { (saber para sentir, saúde para servir) }\end{array}$ & $\begin{array}{l}\text { Honduras, Costa Rica, Colombia. } \\
\text { Brasil }\end{array}$ \\
$\begin{array}{l}\text { Clubes 4-C } \\
\text { (Cabeza, Corazón, Capacidad y }\end{array}$ & Paraguay \\
$\begin{array}{l}\text { Cooperación) } \\
\text { Clubes 5-V } \\
\text { (Valor, Vigor, Verdad, Vergüenza y } \\
\text { Venezuela) }\end{array}$ & Venezuela \\
$\begin{array}{l}\text { Clubes 4-A } \\
\text { (Adiestramiento, Acción, Ayuda y Amistad) } \\
\text { Clubes 4-H } \\
\text { (“head"-cabeza-, "heart" -corazón-, } \\
\text { "hands" -manos-, y “health”-salud-) }\end{array}$ & Argentina \\
\hline
\end{tabular}

Respecto a las acciones destinadas al "Mejoramiento del Hogar", se hallaron por ejemplo: el programa "Mujer Campesina", en Ecuador; en Honduras, la sección de "Demostración en el Hogar"; en Nicaragua, los servicios de "Mejoramiento del Hogar"; y en Argentina el programa "Hogar Rural". 
Finalmente, una vez discontinuada la publicación de la revista en 1967, en coincidencia con la finalización del Proyecto 39, comenzó a publicarse la revista Desarrollo en las Américas, que se edita en forma trimestral a partir de 1968. Se diferencia de la anterior ya que presenta un perfil más científico, donde sólo se publican algunas investigaciones o ensayos seleccionados en español, inglés o portugués, de mayor extensión y profundidad que en la revista anterior, dejando de lado las noticias e información institucional. Además de ampliarse la temática al Desarrollo Rural, incluyendo otros temas de políticas de intervención además de la Extensión Rural, claramente va dirigido a un público profesional más exigente y con un mayor nivel de formación teórica.

Cabe remarcar que ya en los primeros números de esta nueva revista, se observa una visión crítica del modelo de extensión impulsado por EEUU, señalándose que el mismo ha servido sólo para los productores que ya estaban capitalizados antes de la llegada del modelo de modernización agraria impulsado por los Servicios de Extensión. Autores como Samaniego (1971), Freire (1973), Bosco Pinto (1973) y Díaz Bordenave (1976), expresan la necesidad de construir un nuevo enfoque de Extensión Rural que sirva a las necesidades de la gran mayoría de campesinos de Latinoamérica, respetando su identidad y su cultura.

\section{CONCLUSIONES}

Para entender los servicios de extensión latinoamericanos, es preciso conocer su historia. En este trabajo se intentó realizar un pequeño aporte a esa reconstrucción. Se hizo hincapié en analizar la influencia de los EEUU a través de una organización interamericana como fue/es el IICA, en el período desarrollista de posguerra.

Gran parte de los servicios nacionales de extensión rural fueron constituidos y/o consolidados en ese período. La forma y contenido han sido de una semejanza tal que dan cuenta de la influencia de los EEUU, influencia a su vez explicitada en testimonios encontrados en la revista "Extensión en las Américas". La marca realizada por los EEUU se expresó en los propios componentes de los servicios que se constituyeron. La metodología, los objetivos, los destinatarios y las estrategias fueron adoptados casi linealmente, siendo un claro ejemplo del lugar hegemónico que ocupaba EEUU -fundamentalmente respecto al camino a seguir para el logro del desarrollo rural. Confirma esta apreciación el contenido de las "Columnas de Editor" de la revista. Las citas a experiencias y autores del país del norte son recurrentes y dan cuenta de la hegemonía ejercida a nivel conceptual en el campo de la extensión rural.

A su vez, el análisis de los contenidos de la revista, permite reconstruir la estrategia asumida para instalar y consolidar el sistema y la ideología de la Extensión Rural, a partir del establecimiento del IICA en Turrialba y sus oficinas regionales. La estrategia del gobierno estadounidense a través del IICA implicó la puesta en práctica de tres componentes o etapas:

1. Instalación: a) visitas de funcionarios con poder de decisión política de los países latinoamericanos para que observasen el funcionamiento del SEC de EEUU; y b) asignación de expertos norteamericanos a los gobiernos de los distintos países para organizar los Servicios de Extensión.

2. Formación de recursos humanos: a) capacitación de expertos latinoamericanos en EEUU; b) cursos cortos en los distintos países donde se habían creado los Servicios de Extensión; c) Escuela para Graduados 
en países latinoamericanos: donde se forman los primeros Master en Extensión; d) Estudios de Doctorado en Universidades de EEUU.

3. La difusión: la revista es parte del componente para la difusión de los conceptos, las herramientas e instituciones necesarias para el correcto trabajo en extensión.

Desde el punto de vista conceptual, aparece claramente la diferencia, como política de intervención, con el fomento agrícola que se utilizaba en varios países, diferenciándose por el componente educativo de la Extensión Rural y por lo tanto, mostrándose como una propuesta superadora. Para complementar el carácter educativo-persuasivo de la propuesta, el enfoque se apoyó, entre otras cuestiones, en el trabajo con los líderes locales, la planificación normativa y el desarrollo de las habilidades comunicacionales.

Si bien no se explicita en la revista, se puede inferir que los objetivos específicos de la publicación persiguen la intención de:

- Localizar, procesar y difundir información para la toma de decisiones de los dirigentes y de los extensionistas de los países destinatarios.

- Facilitar el acceso a distintas fuentes de información principalmente provenientes de Universidades de EEUU, del Extension Service Review y de las experiencias latinoamericanas.

- Difundir las innovaciones técnico-productivas y organizacionales, que de acuerdo a la visión del IICA sirvan de ejemplo a seguir por parte de los "países subdesarrollados".

Estos objetivos ponen en evidencia la intencionalidad política de la propuesta, al pretender introducir el conocimiento científico en las áreas rurales latinoamericanas y consecuentemente el modo de producción industrial, en el marco que otorgaba la Teoría de la Modernización, como propuesta de desarrollo de la época de la Guerra Fría. También se identifica la intencionalidad de instalar valores fundamentales para la sociedad estadounidense de ese entonces: la familia como núcleo institucional básico de la organización social y la promoción de los liderazgos informales -como mecanismo multiplicador para aumentar la eficiencia del trabajo del extensionista, y dejar instalado localmente recursos humanos que sostengan la propuesta. Cabría preguntarse si este esfuerzo intelectual y práctico por promover los liderazgos locales, se corresponde con una voluntad política de instalar la supuesta función positiva y necesaria de los mismos, y de esa forma, legitimar su propia decisión de asumir una posición hegemónica en el continente.

\section{REFERENCIAS}

ALEMANY, C. E. Elementos para el estudio de la dinámica y evolución histórica de la extensión rural en Argentina. 2012. 518f. Tesis para obtener el título de doctor. Instituto de Sociología y Estudios Campesinos (ISEC). Universidad de Córdoba. España.

ARCE, A. Sociología y desarrollo rural. Turrialba, Costa Rica: IICA, 1963.

ARDILA, J. Extensión Rural para el desarrollo de la agricultura y la seguridad alimentaria: aspectos conceptuales, situación y una visión de futuro. Turrialba, Costa Rica: IICA, 2010. 128 f. 
BARRIENTOS, M. Evolución de los servicios de extensión en nuestro país. Vinculación con los planteos pedagógicos vigentes. Córdoba, Argentina: UNC, 2002.

BARSKY, O. Políticas agrarias en América Latina. Buenos Aires: Imago Mundi, 1990.

PINTO, J. B. Extensión o educación: una disyuntiva crítica. Necesidad de un nuevo planteamiento que busque el cambio estructural. Desarrollo Rural en las Américas, v. V, n. 3, p. 165-186, 1973.

CÁCERES, M. A. Extensión en Honduras. Extensión en las Américas, v. I, n. 5 , 1956.

CAPORAL, F. R. La extensión rural en Rio Grande Do Sul: de la doctrina "Made in USA" hacia el paradigma Agroecológico. In: Encontro Internacional de Empresas de Assistência Técnica. Anais... FIRA, Mazatlan, México, 2001.

CAPORAL, F. R.; COSTABEBER, J. A. Por uma nova extensão rural: fugindo da obsolência. Extensão Rural, n. 2, p. 7-32, 1994.

CASTILLO, A.; LATAPI, P. Educación no formal de adultos en América Latina. Situación actual y perspectivas. In: BARRIENTOS, M. Evolución de los servicios de extensión en nuestro país: Vinculación con los planteos pedagógicos vigentes, Córdoba: UNC, 1984.

COTO M.; R. EI IICA y la OEA. In: IICA. Las ciencias agrícolas en América Latina. Costa Rica: IICA, 1967.

DÍAZ BORDENAVE, J. Communication of agricultural innovations in latin america. the need for new models. Communication Research, v. 3, n. 2, p. 135-154, 1976.

FREIRE, P. Extensión o Comunicación. S XXI Editores. México, 1973.

GRACIARENA, J. El estado latinoamericano en perspectiva: figuras, crisis, prospectiva. Buenos Aires: Eudeba, 2000.

GUZMÁN, E. S. Desde el pensamiento social agrario: Perspectivas agroecológicas. España: Universidad de Córdoba, Instituto de Sociología y Estudios Campesinos, 2006.

IICA. EI IICA y su historia: 50 años de cooperación interamericana. San José, Costa Rica: IICA, 1992.

MAUNDER, A. Why an Extension Service Today in Other Countries? In: SANDERS, et al, The cooperative extension service, Londres: Prentice-Hall, 1966.

PUERTA, T. F. S. Extensión agraria y desarrollo rural: sobre la evolución de las teorías y praxis extensionistas. Madrid: MAPyA, 1996.

RAIGADA, J. L. P. Epistemología, metodología y técnicas del análisis de contenido. Sociolinguistic Studies, v. 3, n. 1, p. 1-42, 2002. 
ROBERTS, W. Así fue creado el Servicio de Extensión. Extensión en las Américas, v. I, n. 2, 1956.

RUBIO, J. F. Extensión Agrícola en Guatemala empieza a invadir el país. Extensión en las Américas, v. I, n. 3, 1956.

RUIZ, C. Extensión en Ecuador. Extensión en las Américas, v. II, n. 2, 1957.

SAMANIEGO, C. Aspectos sociológicos para un nuevo enfoque de la Extensión rural. Necesidad de una organización integrada y comprometida con el proceso de desarrollo elegido. Desarrollo rural en las Américas, Vol. III. n. 3, p. 45-54, 1971.

SAMPAIO, P. A. La reforma agraria en América Latina: una revolución frustrada. OSAL: Observatorio Social de América Latina, año 6, n. 16, p. 15-22, 2005.

SMITH y WILSON. The agricultural extensión system of United States. New York: John Wiley \& Sons Inc, 1930.

TORRES, A. Fue unificado el servicio de Extensión Agrícola del Ecuador. Extensión en las Américas, v. III, n. 4, 1958. 